\title{
Antenatal Myomectomy: Is It Safe?
}

\author{
Nor Amirawati A, Anizah A( () , Shafiee MN \\ Department of Obstetrics and Gynaecology, Faculty of Medicine, Universiti Kebangsaan Malaysia \\ Medical Centre, Jalan Yaacob Latif, Bandar Tun Razak, 56000 Cheras, Kuala Lumpur, Malaysia.
}

\begin{abstract}
Myomectomy is rarely performed in pregnancy due to risk of miscarriage or pregnancy loss, bleeding and possible hysterectomy. Myomectomy is mainly reserved for unavoidable indications such as rapidly growing fibroid or severe pain with possiblity of red degeneration for which medical treatment failed. However, good outcome had been reported in selective second trimester myomectomies.
\end{abstract}

Keywords: $\quad$ Antenatal, leiomyomas, myomectomy, pregnancy, safety, uterine fibroid

\section{Correspondence:}

Anizah Ali. Faculty of Medicine, Universiti Kebangsaan Malaysia Medical Centre, Jalan Yaacob Latif, Bandar Tun Razak, 56000 Cheras, Kuala Lumpur, Malaysia. Tel: +60391455960 Fax: +603-91456672 Email: anizahali.dr@gmail.com

\section{Introduction}

The prevalence of leiomyomas during pregnancy varies from 0.3 to $15 \%$ (1). Leiomyomas mostly remains asymptomatic during pregnancy but in $10 \%$ of cases, it causes obstetric complications depending on their size, location, and number (2). Pain is the most common symptom reported however it rarely necessitates myomectomy (3). To date, limited literature exists to serve as reference with regards myomectomy in pregnancy. Available literatures are mainly restricted to case reports and retrospective studies. As such, a surgical approach is usually reserved for cases of intractable abdominal pain or persistent gastroenteric and urinary symptoms despite pharmacological treatment (4-6). Majority of the reported myomectomies were performed in second trimester for intractable pelvic pain and had excellent results. We are reporting two cases of unavoidable myomectomies in second trimester with good outcome throughout the pregnancy $(7,8)$.

\section{Case Report}

Case 1

A 28-year old primigravida presented with severe right iliac fossa pain and mass per abdomen at 13 weeks and 5 days period of amenorrheoa. She experienced it for 2 days prior to presentation. She had sudden onset of pain with pain score of 7/10. There were no aggravating factors and the pain was not radiating. She was unable to sit up for a long time and thus affected her daily activities. Otherwise, there were no urinary or bowel symptoms.

Assessment revealed that she was in pain and distressed. She was tachycardic but remained stable and a febrile. Abdomen was soft but tender with voluntary guarding. Uterus was palpable at 16 weeks size with a right iliac fossa mass measuring $6 \times 6 \mathrm{~cm}$. The mass has normal overlying skin, regular border, firm in consistency and mobile side to side but unable 
to get below the mass. Vaginal examination revealed normal vulva and vagina, cervix was tubular and os closed. Uterus was at 16 weeks size bimanually and mass was attached to uterus. Other systems were unremarkable.

Investigations showed she had normochromic normocytic anaemia with haemoglobin of $10.8 \mathrm{~g} / \mathrm{dL}$, white cell count was normal $7.8 \times 109 / \mathrm{L}$ and normal platelet level. A pedunculated fibroid which measured $6.8 \times 6.6 \mathrm{~cm}$ was seen on transabdominal ultrasound. There were no complex appearance or cystic changes noted. Fetus was viable with parameters corresponded to her gestational age and placenta was posterior not low lying.

Diagnosis of penduculated uterine fibroid was made. She was treated with regular intravenous opiods. However, despite adequate analgesia, her pain score was not reduced. She was then subjected for emergency laparotomy myomectomy due to intractable pain having failed medical management. Upon entry to her pelvis, uterus was noted to be enlarged to 16 weeks size with a subserosal fibroid at right posterolateral wall (Fig. 1). It measured $6 \times 8 \mathrm{~cm}$ and had paper thin stretched subserosal layer covering the tumour. Myomectomy procedure was uneventful, uterine incision was closed with vicryl $1 / 0$. Hemostatic agent also was placed at incision site and estimated blood loss was only 200ml. Symptoms markedly improved post-operatively and she was discharged home the subsequent day. Histopathology report showed interlacing fibers of smooth muscle with spindle shaped cells, bland looking and elongated nuclei with abundant eosinophilic cytoplasm. There were also dilated and congested blood vessels of variable sizes. Extensive area of hyalinization and areas of infarct were noted with no evidence of atypia or malignancy. She progressed to term without complications. She delivered a baby boy weighing $3.4 \mathrm{~kg}$ via emergency caesarean section due to fetal distress.

\section{Case 2}

A 27-year-old primigravida first seen in antenatal clinic at 16 weeks period of amenorrheoa. During routine ultrasound, she was noted to have lower segment uterine fibroid measuring $7.8 \times 7.1 \mathrm{~cm}$. Foetal parameters corresponded to her gestational age. Initially, she remained asymptomatic until at 17 weeks period of amenorrheoa when she started experiencing pain at suprapubic area which persisted despite regular analgesia. As such, she requested for surgical intervention. Intraoperatively a left broad ligament fibroid which measured 8 x 9cm was discovered (Fig.
2). Both ovaries and fallopian tubes were normal. Myomectomy performed and it was uneventful. Estimated blood loss was 200ml. Histopathology report confirmed leiomyoma. Her pregnancy progressed well till postdate 3 days. She successfully delivered a healthy baby boy weighing $3.35 \mathrm{~kg}$ via emergency caesarean section for poor progress.

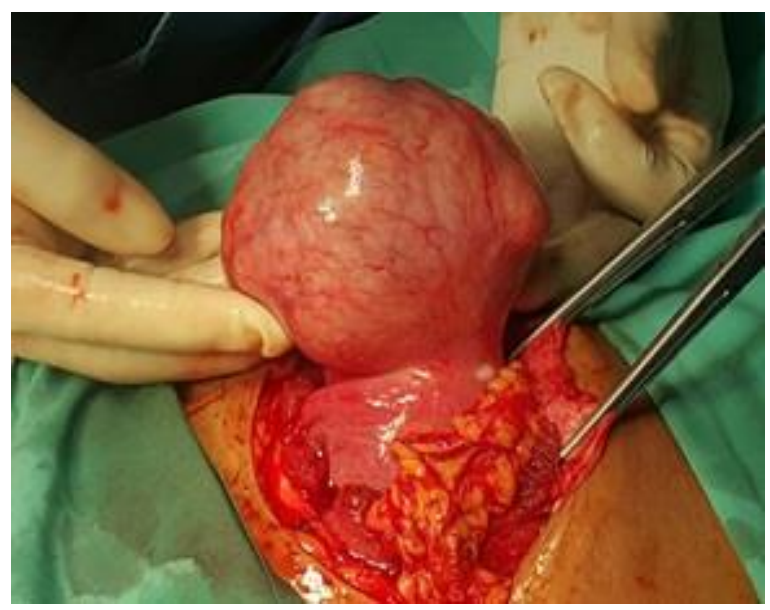

Figure 1: Penduculated subserosal myoma

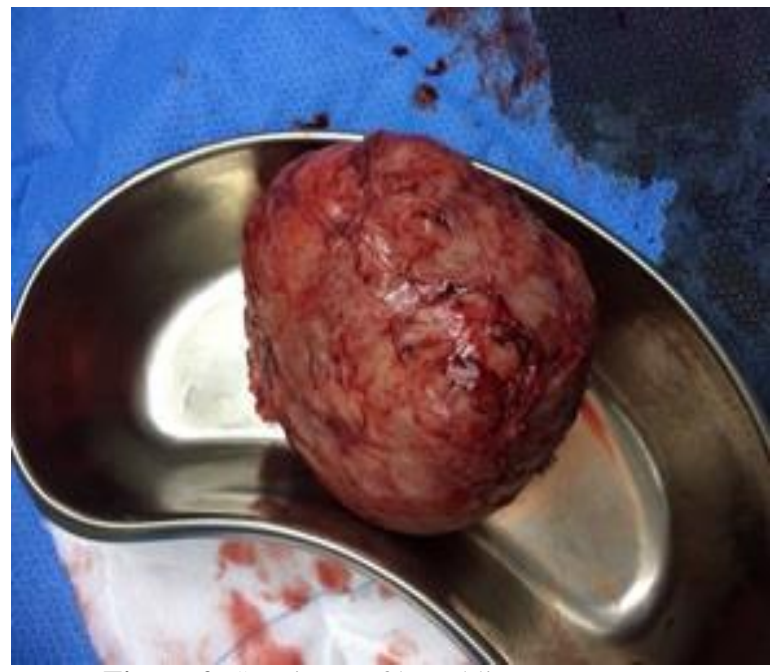

Figure 2: Specimen of broad ligament myoma

\section{Discussion}

Leiomyomas are benign smooth muscle tumours of the uterus and is the most frequently seen tumours in reproductive age group. Although most pregnant women with leiomyomatas remain asymptomatic, the potential risk of severe pain secondary to red degeneration may cause concern to both; the patient and the managing obstetrician. The potential effects of fibroids on pregnancy and the potential effects of pregnancy on fibroids usually raise clinical concern although most pregnant women with leiomyomas do not have any complications related to it. Pain is the 
most common complaint encountered in pregnancy although leiomyomas in pregnancy may also increase the risk of obstetrics complications such as miscarriage, premature labour and delivery, malpresentation of fetus, and placental abruption. Removal of leiomyomas or myomectomy during pregnancy has previously been reserved for cases of severe intractable pain that have failed conservative management. Myomectomy itself during pregnancy carries risk of miscarriage, pregnancy loss, bleeding and the much feared possiblity of hysterectomy for cases of intractable bleeding. Conventional teaching advocate avoiding myomectomy in pregnancy for all the above associated risks (9). However, current practice has changed. Myomectomy could also be done in pregnancy. Limited available literatures showed that myomectomy is best and safest to be perform in the second trimester, provided the cavity is not breached.

Mollica et al. conducted a prospective study of 106 pregnant women with uterine myomas who were admitted for recurrent pain, large or rapidly growing myomas in varied size and site or myomas deforming the placental site (7). She found that pregnant women who underwent myomectomy had better pregnancy outcomes compared to those managed conservatively. The outcomes proved superior in terms of pregnancy loss, premature rupture of membranes, preterm labor and need for Caesarean hysterectomy.

Traditionally myomectomy in pregnancy is generally avoided. However, in the face of increasing of evidence, the obstetrician could be reassured that second trimester myomectomy is considered a safe option in selected patients and under the hand of an experienced surgeon (10). Therefore, with better outcomes as were reported, it could further strengthen the safety of the procedure and feasibility of new management approach for antenatal fibroids.

\section{Conclusion}

Antenatal myomectomy can be a safe option of treatment for intractable pain secondary to uterine fibroid that failed conservative measures. Complications related to antenatal myomectomy can be avoided with proper case selection, counselling and experienced surgeon.

\section{References}

1. Cooper NP, Okolo S. Fibroids in pregnancycommon but poorly understood. Obstet Gynecol Surv 2005; 60(2): 132-8.

2. Phelan P. Myomas and pregnancy. Obstet Gynecol Clin North Am 1995; 22(4): 801-5.

3. Lee HJ, Norwitz ER, Shaw J. Contemporary Management of Fibroids in Pregnancy. Rev Obstet Gynecol 2010; 3(1): 20-7.

4. Lolis DE, Kalantaridou SN, Makrydimas G, et al. Successful myomectomy during pregnancy. Hum Reprod 2003;18(8): 1699-702.

5. Bonito M, Gulemì L, Basili R, Roselli D. Myomectomy during the first and second trimester of pregnancy. Clin Exp Obstet Gynecol 2007; 34(3): 149-50.

6. Lozza V, Pieralli A, Corioni S, Longinotti M, Penna C. Multiple laparotomic myomectomy during pregnancy: A case report. Arch Gynecol Obstet 2011; 284(3): 613-6.

7. Mollica G, Pittini L, Minganti E, Perri G, Pansini F. Elective uterine myomectomy in pregnant women. Clin Exp Obstet Gynecol. 1996; 23(3): 168-72.

8. Celik C, Acar A, Ciçek N, Gezginc K, Akyürek C. Can myomectomy be performed during pregnancy? Gynecol Obstet Invest 2002; 53(2): 79-83.

9. Febo G, Tessarolo M, Leo L, Arduino S, Wierdis T, Lanza L. Surgical management of leiomyomata in pregnancy. Clin Exp Obstet Gynecol 1997; 24(2): 76-8.

10. Domenici L, Di Donato V, Gasparri ML, Lecce F, Caccetta J, Panici PB. Laparotomic myomectomy in the 16th week of pregnancy: a case report. Case Rep Obstet Gynecol 2014; 2014: 154347 . 